\title{
In vitro activities of I I fluoroquinolones against 8 I 6 non-typhoidal strains of Salmonella enterica isolated from Finnish patients with special reference to reduced ciprofloxacin susceptibility
} Pirkko Kotilainen*1,2, Susa Pitkänen ${ }^{1,2}$, Anja Siitonen ${ }^{3}$, Pentti Huovinen ${ }^{1}$ and Antti J Hakanen ${ }^{1,2}$

Address: ${ }^{1}$ Antimicrobial Research Laboratory, Department of Bacterial and Inflammatory Diseases, National Public Health Institute, Turku, Finland, ${ }^{2}$ Department of Medicine, Turku University Hospital and Turku University, Turku, Finland and ${ }^{3}$ Enteric Bacteria Laboratory, Department of Bacterial and Inflammatory Diseases, National Public Health Institute, Helsinki, Finland

Email: Pirkko Kotilainen* - pirkko.kotilainen@utu.fi; Susa Pitkänen - susa.pitkanen@utu.fi; Anja Siitonen - anja.siitonen@ktl.fi; Pentti Huovinen - pentti.huovinen@ktl.fi; Antti J Hakanen - antti.hakanen@utu.fi

* Corresponding author

This article is available from: http://www.ann-clinmicrob.com/content/4/I//2

(c) 2005 Kotilainen et al; licensee BioMed Central Ltd.

This is an Open Access article distributed under the terms of the Creative Commons Attribution License (http://creativecommons.org/licenses/by/2.0), which permits unrestricted use, distribution, and reproduction in any medium, provided the original work is properly cited.

\begin{abstract}
Background: The number of Salmonella strains with reduced susceptibility to fluoroquinolones has increased during recent years in many countries, threatening the value of this antimicrobial group in the treatment of severe salmonella infections.

Methods: We analyzed the in vitro activities of ciprofloxacin and 10 additional fluoroquinolones against 816 Salmonella strains collected from Finnish patients between 1995 and 2003. Special attention was focused on the efficacy of newer fluoroquinolones against the Salmonella strains with reduced ciprofloxacin susceptibility.

Results: The isolates represented II 9 different serotypes. Of all 816 Salmonella strains, $3(0.4 \%)$ were resistant to ciprofloxacin (MIC $\geq 4 \mu \mathrm{g} / \mathrm{ml}), 232$ (28.4\%) showed reduced susceptibility to ciprofloxacin (MIC $\geq 0.125-2 \mu \mathrm{g} / \mathrm{ml}$ ), and $58 \mathrm{I}\left(7 \mathrm{I} .2 \%\right.$ ) were ciprofloxacin-susceptible. The $\mathrm{MIC}_{50}$ and $\mathrm{MIC}_{90}$ values of ciprofloxacin for these strains were 0.032 and $0.25 \mu \mathrm{g} / \mathrm{ml}$, respectively, being lower than those of the other fluoroquinolone compounds presently on market in Finland (ofloxacin, norfloxacin, levofloxacin, and moxifloxacin). For two newer quinolones, clinafloxacin and sitafloxacin, the $\mathrm{MIC}_{50}$ and $\mathrm{MIC}_{90}$ values were lowest, both 0.016 and $0.064 \mu \mathrm{g} / \mathrm{ml}$, respectively. Moreover, clinafloxacin and sitafloxacin exhibited the lowest $\mathrm{MIC}_{50}$ and $\mathrm{MIC}_{90}$ values, 0.064 and $0.125 \mu \mathrm{g} / \mathrm{ml}$, against the 235 Salmonella strains with reduced susceptibility and strains fully resistant to ciprofloxacin.
\end{abstract}

Conclusion: Among the registered fluoroquinolones in Finland, ciprofloxacin still appears to be the most effective drug for the treatment salmonella infections. Among the newer preparations, both clinafloxacin and sitafloxacin are promising based on in vitro studies, especially for strains showing reduced ciprofloxacin susceptibility. Their efficacy, however, has not been demonstrated in clinical investigations. 


\section{Background}

Fluoroquinolones generally have a good in vitro and clinical activity against isolates of the Salmonella species [1]. Although the Clinical and Laboratory Standards Institute (CLSI; formerly the National Committee for Clinical Laboratory Standards, NCCLS) guidelines recommend the MICs of $\leq 1$ and $\geq 4 \mu \mathrm{g} / \mathrm{ml}$ as respective breakpoints of susceptibility and resistance to ciprofloxacin [2], it is now commonly accepted that Salmonella isolates with MICs between $\geq 0.125$ and $2 \mu \mathrm{g} / \mathrm{ml}$ are characterized by reduced susceptibility i.e. low-level resistance to fluoroquinolones. The selection of MICs $\geq 0.125 \mu \mathrm{g} / \mathrm{ml}$ as a breakpoint of reduced ciprofloxacin susceptibility is justified based on histogram and scatterblot analyses combined with sequencing data [3-8]. This selection is further supported by reports on several treatment failures with ciprofloxacin and other fluoroquinolones in patients with infections caused by Salmonella strains showing reduced susceptibility to fluoroquinolones [9-17].

It is of concern that in recent years, the number of Salmonella isolates with reduced fluoroquinolone susceptibility has increased in many countries, including countries of the European Union [6,18-21]. In Finland, reduced fluoroquinolone susceptibility emerged between 1995 and 1997 among Salmonella isolates of domestic origin [21], and a significant increase in the annual proportion of reduced fluoroquinolone susceptibility was observed between 1995 and 1999 among both the domestic and foreign isolates [5].

Several fluoroquinolone preparations are on market all over the world, while a number of new compounds are presently being developed or undergoing clinical studies. The purpose of the present study was to determine the in vitro activities of various older and newer fluoroquinolones towards the Salmonella species, focusing special attention on the isolates with reduced ciprofloxacin susceptibility. In so doing, we determined the susceptibilities of 816 epidemiologically unrelated Salmonella isolates to ciprofloxacin and 10 additional fluoroquinolones including two novel extended-spectrum compounds: clinafloxacin and sitafloxacin.

\section{Methods}

\section{Salmonella strains}

Antimicrobial susceptibility of Salmonella enterica isolates has been surveyed in the National Public Health Institute, Finland, since 1995 by analyzing yearly 200-400 strains collected from Finnish patients seeking medical assistance for gastroenteritis. Starting in January each year, we consecutively collect $100-200$ foreign strains and 100-200 domestic (i.e., Finnish) strains for susceptibility testing. An isolate is designated as of foreign origin, if the patient has reported travel abroad during one month before the specimen day. All other isolates are designated as of domestic origin. Epidemiological information regarding potential travelling and the travel destination is collected from the forms which accompany each isolate sent to the Enteric Bacteria Laboratory of the National Public Health Institute, Helsinki, which serves as the National Salmonella Reference Centre in Finland.

We included in this study a total of 816 clinical Salmonella strains collected between 1995 and 2003 during the annual surveys. All strains were isolated from stool. Of these strains, 365 were designated as of domestic origin and 451 as of foreign origin. The strains were considered to be epidemiologically unrelated based on their recovery from distinct sources. For each Salmonella outbreak recognized, only one isolate representing the epidemic strain was included. The Salmonella collection consisted of 119 different serotypes. All strains belonged to non-typhoidal Salmonella enterica. The most prevalent serotypes were $S$. Enteritidis, $S$. Typhimurium, and $S$. Hadar, accounting for $27.2 \%, 19.0 \%$, and $7.1 \%$ of the isolates, respectively.

\section{Susceptibility testing}

The minimum inhibitory concentrations (MIC) of the isolates were determined by the standard agar plate dilution method according to the NCCLS guidelines [22]. MuellerHinton II agar (BBL, Becton Dickinson and Company, Cockeysville, Md.) was used as the culture medium. Altogether 11 fluoroquinolone compounds were analyzed. Reagent powder of each of these agents was provided by its manufactorer: ciprofloxacin (Bayer, Wuppertal, Germany), clinafloxacin (Pfizer, Ann Arbor, MI, Unites States), enrofloxacin (Bayer, Elberfeld, Germany), gatifloxacin (Grunenthal BHBH, Aachen, Germany), gemifloxacin (GlaxoSmithKline, Worthing, United Kingdom), levofloxacin (Hoechst Marion Roussel, Romainville Cedex, France), lomefloxacin (Sigma, St. Luis, MO, United States), moxifloxacin (Bayer, Wuppertal, Germany), norfloxacin and ofloxacin (Sigma, Steinheim, Germany), and sitafloxacin (Daiichi Pharmaceuticals, Tokyo, Japan). The Salmonella isolates were also tested for susceptibility to nalidixic acid.

Of the fluoroquinolone compounds analyzed, ciprofloxacin, ofloxacin, norfloxacin, levofloxacin, and moxifloxacin are presently on market in Finland.

Staphylococcus aureus ATCC 29213, Escherichia coli ATCC 25922, E. coli ATCC 35218, and Pseudomonas aeruginosa ATCC 27853 were used as controls in susceptibility testing. 


\section{Data analysis}

The susceptibility data were analyzed using the WHONET5 computer program (available from http:// www.who.int/drugresistance/whonetsoftware/en/).

\section{Results}

Of all 816 Salmonella strains, $3(0.4 \%)$ were resistant to ciprofloxacin (MIC $\geq 4 \mu \mathrm{g} / \mathrm{ml}$ ), 232 (28.4\%) showed reduced susceptibility to ciprofloxacin (MIC $\geq 0.125-2$ $\mu \mathrm{g} / \mathrm{ml})$, and $581(71.2 \%)$ were ciprofloxacin-susceptible. Of the 451 foreign Salmonella strains, 2 (0.4\%) were ciprofloxacin-resistant and $193(42.8 \%)$ showed reduced susceptibility to ciprofloxacin. Of the 365 domestic Salmonella strains, $1(0.3 \%)$ was ciprofloxacin-resistant and 39 (10.7\%) showed reduced susceptibility to ciprofloxacin.

For all 816 strains, the $\mathrm{MIC}_{50}$ and $\mathrm{MIC}_{90}$ values of ciprofloxacin were 0.032 and $0.25 \mu \mathrm{g} / \mathrm{ml}$, respectively (Table 1). For ofloxacin, levofloxacin, norfloxacin, and moxifloxacin, the $\mathrm{MIC}_{50}$ values varied between 0.064 and $0.125 \mu \mathrm{g} / \mathrm{ml}$; and the $\mathrm{MIC}_{90}$ values, between 0.5 and $1 \mu \mathrm{g} /$ $\mathrm{ml}$. The $\mathrm{MIC}_{50}$ and $\mathrm{MIC}_{90}$ values of enrofloxacin, lomefloxacin, gatifloxacin, and gemifloxacin were similar to or higher than those of ciprofloxacin. For both clinafloxacin and sitafloxacin, the $\mathrm{MIC}_{50}$ and $\mathrm{MIC}_{90}$ values were lower than for the other agents tested, 0.016 and $0.064 \mu \mathrm{g} / \mathrm{ml}$, respectively. The histograms illustrating the MICs of the fluoroquinolones studied are presented in Figure 1. The $\mathrm{MIC}_{50}$ and $\mathrm{MIC}_{90}$ values of nalidixic acid were 4 and 512 $\mu \mathrm{g} / \mathrm{ml}$, respectively (range, $<0.5$ to $>512 \mu \mathrm{g} / \mathrm{ml}$ ).

The most prevalent serotypes among the 235 Salmonella strains with reduced susceptibility or resistance to ciprofloxacin were $S$. Hadar, S. Enteritidis, and S. Virchow accounting for $22.6 \%, 20.9 \%$, and $12.3 \%$ of the strains, respectively. For these 235 strains, the $\mathrm{MIC}_{50}$ values of ofloxacin, levofloxacin, norfloxacin and moxifloxacin varied between 0.5 and $1 \mu \mathrm{g} / \mathrm{ml}$; and the $\mathrm{MIC}_{90}$ value was 1 $\mu \mathrm{g} / \mathrm{ml}$ for all (Table 2). The $\mathrm{MIC}_{50}$ and $\mathrm{MIC}_{90}$ values were lowest, 0.064 and $0.125 \mu \mathrm{g} / \mathrm{ml}$, for both clinafloxacin and sitafloxacin. For the additional 4 fluoroquinolones examined, the $\mathrm{MIC}_{50}$ varied between 0.25 and $2 \mu \mathrm{g} / \mathrm{ml}$; and the $\mathrm{MIC}_{90}$ values, between 0.5 and $2 \mu \mathrm{g} / \mathrm{ml}$. The $\mathrm{MIC}_{50}$ and $\mathrm{MIC}_{90}$ values of nalidixic acid for these strains were 512 and $>512 \mu \mathrm{g} / \mathrm{ml}$, respectively (range, 4 to $>512 \mu \mathrm{g} / \mathrm{ml}$ ).

The scattergrams correlating the MICs of ciprofloxacin to those of clinafloxacin, levofloxacin, moxifloxacin, norfloxacin, ofloxacin, and sitafloxacin for the 816 Salmonella strains are presented in Figure 2. These pictures illustrate that there is a distinct correlation between the ciprofloxacin susceptibility and the susceptibility to other fluoroquinolones. The MICs of levofloxacin, moxifloxacin, norfloxacin, and ofloxacin were generally higher than those of ciprofloxacin, but for each, the fully susceptible population was separate from the population with reduced susceptibility. Of the 232 Salmonella strains with reduced ciprofloxacin susceptibility, the MICs of levoxacin, moxifloxacin, norfloxacin, and ofloxacin were 1 or 2 dilution steps higher than those of ciprofloxacin. In contrast, the MICs of clinafloxacin and sitafloxacin were generally 2 dilution steps lower than those of ciprofloxacin.

\section{Discussion}

Of all 816 Salmonella strains included in the present study, $28.8 \%$ showed resistance or reduced susceptibility to ciprofloxacin. The $\mathrm{MIC}_{50}$ and $\mathrm{MIC}_{90}$ values of ciprofloxacin for these isolates were 0.032 and $0.25 \mu \mathrm{g} / \mathrm{ml}$, respectively, being similar to or lower than those of all older fluoroquinolone compounds studied. Thus, we show that ciprofloxacin still is the most effective fluoroquinolone drug registered in Finland for the treatment of salmonellosis. In the entire Salmonella collection, the $\mathrm{MIC}_{50}$ and $\mathrm{MIC}_{90}$ values were lowest for two new quinolones: clinafloxacin and sitafloxacin. Moreover, clinafloxacin and sitafloxacin exhibited the lowest $\mathrm{MIC}_{50}$ and $\mathrm{MIC}_{90}$ values for the 235 ciprofloxacin-resistant Salmonella strains or strains showing reduced ciprofloxacin susceptibility. Based on these in vitro results, both clinafloxacin and sitafloxacin appear promising drugs for the treatment of salmonella infections, but their efficacy has not been demonstrated in clinical investigations.

The introduction of fluoroquinolones in the 1980's had an almost revolutionary effect on the treatment of salmonellosis, since they offered an effective per oral alternative to treat clinical infections as well as to eradicate long-term carriage. So far, the emergence and rapid increase of reduced fluoroquinolone susceptibility in non-typhoidal salmonellas has not led to major consequences, since these microbes characteristically cause gastroenteritis, for which antimicrobial treatment is not always indicated. The situation is totally different in invasive salmonella infections, in which administration of an effective antimicrobial agent is vitally important. If such an infection is caused by a Salmonella strain with reduced fluoroquinolone susceptibility, treatment with a fluoroquinolone compound may not be a safe alternative. There are several reports showing that the use of fluoroquinolones in infections caused by Salmonella isolates with reduced susceptibility may lead to treatment failures [6-17]. The majority of the cases have involved Salmonella enterica serotype Typhi $[8,10-12,15]$. In non-typhoidal salmonellosis, the causative strain has often been initially fully susceptible, but after fluoroquinolone treatment failure, the MICs for these strains have been $\geq 0.125 \mu \mathrm{g} / \mathrm{ml}[13,14,17]$.

Clinafloxacin and sitafloxacin are the most interesting fluoroquinolone compounds studied here, since earlier 

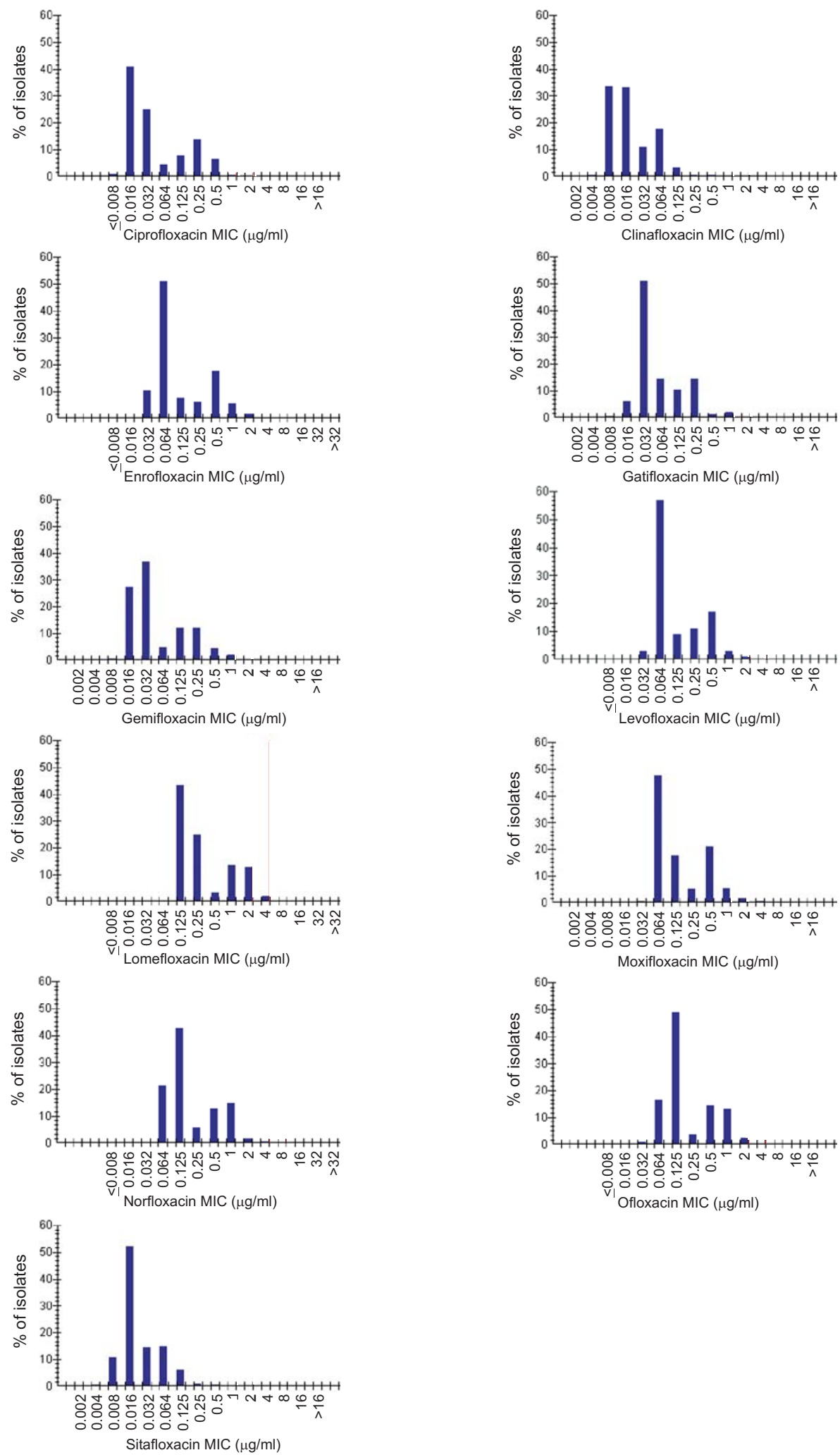

Figure I

MIC histograms of fluoroquinolones. Minimum inhibitory concentration (MIC) histograms of II fluoroquinolones against 816 Salmonella strains collected from Finnish patients between January 1995 and January 2003. 
Table I: MICs of I I fluoroquinolones for 8 I 6 non-typhoidal strains of Salmonella enterica isolated from Finnish patients between I995 and 2003

\begin{tabular}{|c|c|c|c|c|}
\hline \multirow[b]{2}{*}{ Fluoroquinolone } & \multicolumn{4}{|c|}{ MIC $(\mu \mathrm{g} / \mathrm{ml})$} \\
\hline & Number of isolates & $\mathrm{MIC}_{50}$ & $\mathrm{MIC}_{90}$ & Range \\
\hline Ciprofloxacin & 816 & 0.032 & 0.25 & $0.008-16$ \\
\hline Clinafloxacin & 816 & 0.016 & 0.064 & $0.002-2$ \\
\hline Enrofloxacin & 808 & 0.064 & 0.5 & $0.032->32$ \\
\hline Gatifloxacin & 816 & 0.032 & 0.25 & $0.002-8$ \\
\hline Gemifloxacin & 815 & 0.032 & 0.25 & $0.002->16$ \\
\hline Levofloxacin & 808 & 0.064 & 0.5 & $\leq 0.008-16$ \\
\hline Lomefloxacin & 807 & 0.25 & 2 & $0.064->32$ \\
\hline Moxifloxacin & 816 & 0.125 & 0.5 & $0.008->16$ \\
\hline Norfloxacin & 816 & 0.125 & 1 & $0.016->32$ \\
\hline Ofloxacin & 816 & 0.125 & I & $0.016->16$ \\
\hline Sitafloxacin & 816 & 0.016 & 0.064 & $0.002-2$ \\
\hline
\end{tabular}

Table 2: MICs of I I fluoroquinolones for 235 non-typhoidal strains of Salmonella enterica with reduced ciprofloxacin susceptibility' or ciprofloxacin resistance ${ }^{2}$ isolated from Finnish patients between 1995 and 2003

\begin{tabular}{|c|c|c|c|c|}
\hline \multirow[b]{2}{*}{ Fluoroquinolone } & \multicolumn{4}{|c|}{ MIC $(\mu g / m l)$} \\
\hline & Number of isolates & $\mathrm{MIC}_{50}$ & $\mathrm{MIC}_{90}$ & Range \\
\hline Ciprofloxacin & 235 & 0.25 & 0.5 & $0.125-16$ \\
\hline Clinafloxacin & 235 & 0.064 & 0.125 & $0.008-2$ \\
\hline Enrofloxacin & 233 & 0.5 & 1 & $0.032->32$ \\
\hline Gatifloxacin & 235 & 0.25 & 0.5 & $0.032-8$ \\
\hline Gemifloxacin & 235 & 0.25 & 0.5 & $0.064->16$ \\
\hline Levofloxacin & 233 & 0.5 & I & $0.064-16$ \\
\hline Lomefloxacin & 232 & 2 & 2 & $0.25->32$ \\
\hline Moxifloxacin & 235 & 0.5 & I & $0.25->16$ \\
\hline Norfloxacin & 235 & I & I & $0.25->32$ \\
\hline Ofloxacin & 235 & i & i & $0.125->16$ \\
\hline Sitafloxacin & 235 & 0.064 & 0.125 & $0.016-2$ \\
\hline
\end{tabular}

'Ciprofloxacin MIC $\geq 0.125-2 \mu g / \mathrm{ml}$

${ }^{2}$ Ciprofloxacin MIC $\geq 4 \mu \mathrm{g} / \mathrm{ml}$

data on their activity against the Salmonella species are limited. We found only one previous study, in which the in vitro activity of sitafloxacin against 326 Salmonella isolates was tested, with a finding that its activity was equal to or slightly better than that of ciprofloxacin [23].

One of the main purposes of the present study was to analyze the in vitro activities of these two novel fluoroquinolone compounds towards Salmonella isolates with reduced ciprofloxacin susceptibility. Our results show that the $\mathrm{MIC}_{50}$ and $\mathrm{MIC}_{90}$ of clinafloxacin and sitafloxacin against these strains were generally 2 dilution steps lower than those of ciprofloxacin and even 4 to 5 dilution steps lower than some of the older fluoroquinolones. Nevertheless, this does not necessarily mean that they should have a superior in vivo activity. The fluoroquinolone antimicrobial group is characterized by cross resistance, indicating that when a bacterial isolate is resistant to one fluoroquinolone, it is also resistant to other members of the same group [24].

The development of fluoroquinolone resistance most commonly involves a mutation in the quinolone resistance determining region (QRDR) of the grrA gene $[4,5,14,25,26]$. One single point mutation usually leads to nalidixic acid resistance and reduced fluoroquinolone 
Figure 2
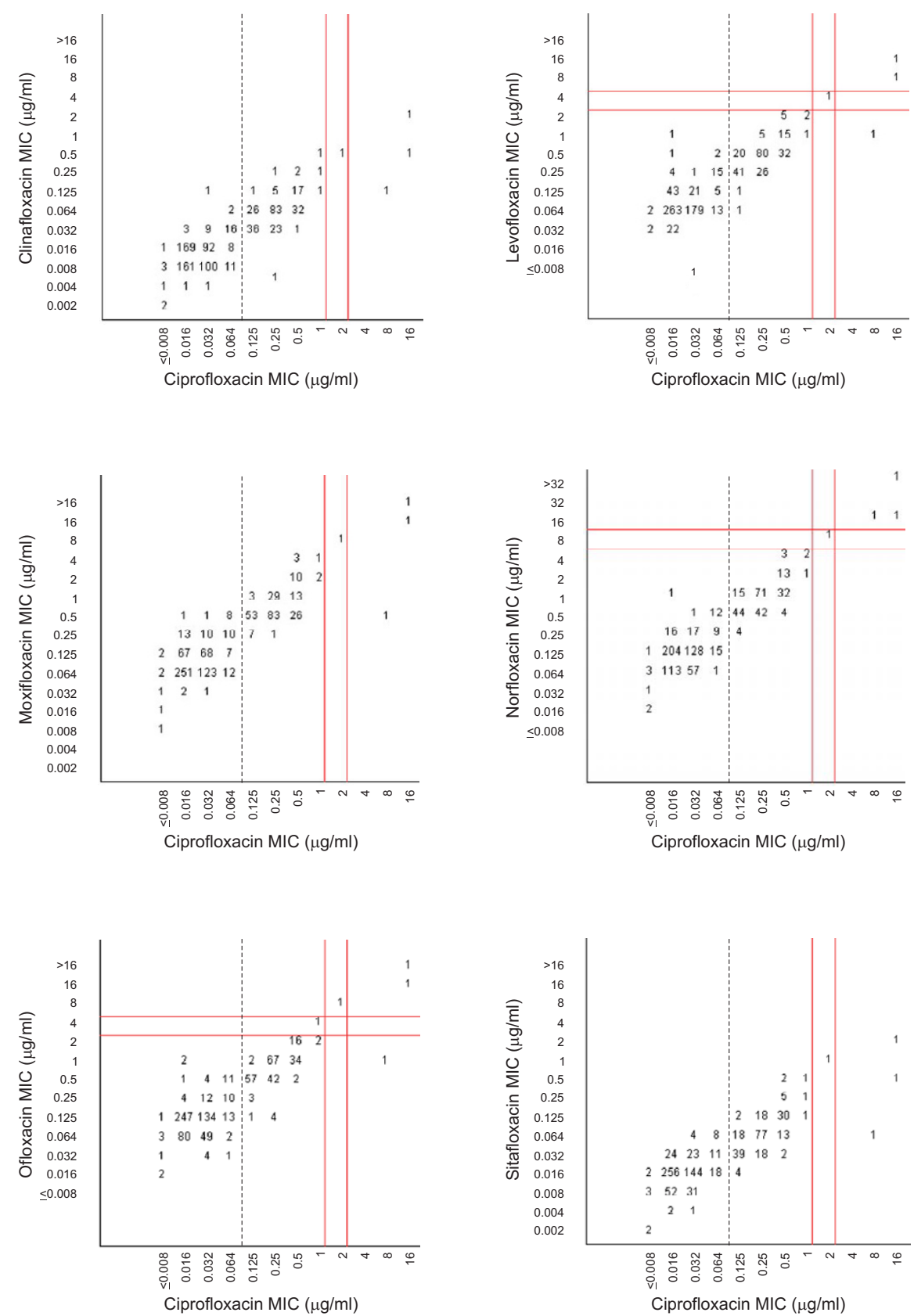

\section{Figure 2}

Scattergrams correlating the MICs of ciprofloxacin to those of other fluoroquinolones. Scattergrams for 816 Salmonella strains correlating the minimum inhibitory concentrations (MIC) of ciprofloxacin to those of clinafloxacin, levofloxacin, moxifloxacin, norfloxacin, ofloxacin, and sitafloxacin. The numbers within the graphs indicate the numbers of Salmonella strains. The vertical solid lines indicate the Clinical and Laboratory Standards Istitute (CLSI) breakpoint recommendations for susceptibility and resistance, respectively, to ciprofloxacin (MIC $\leq \mathrm{I}$ and $\geq 4 \mu \mathrm{g} / \mathrm{ml}$ ); and the vertical dashed lines, the breakpoint for reduced susceptibility (MIC $\geq 0.125 \mu \mathrm{g} / \mathrm{ml}$ ). The horizontal solid lines indicate the respective CLSI breakpoint recommendations to those fluoroquinolones for which such recommendations are available: ofloxacin (MIC $\leq 2$ and $\geq 8 \mu \mathrm{g} / \mathrm{ml}$ ); norfloxacin (MIC $\leq 4$ and $\geq 16 \mu \mathrm{g} / \mathrm{ml}$ ); and levofloxacin (MIC $\leq 2$ and $\geq 8 \mu \mathrm{g} / \mathrm{ml}$ ). 
susceptibility, while additional mutations or accumulation of several resistance mechanisms are needed to produce high-level fluoroquinolone resistance. On this basis, one can assume that in the majority of the Salmonella strains with reduced fluoroquinolone susceptibility analyzed here, quinolone resistance is associated with one point mutation. Based on their low MIC values, both clinafloxacin and sitafloxacin may potentially have useful clinical activity against Salmonella strains with a single mutation in the gyrA gene. It must be borne in mind, however, that having undergone one point mutation, these isolates are potentially inclined to a second mutation, leading to higher MIC values. Thus, it is probable that resistance will develop during fluoroquinolone treatment also against these newer quinolones, despite their initially low MIC values.

It is also of note that the clinical relevance of various MIC values of clinafloxacin and sitafloxacin is not known. Further, no breakpoins of resistance or susceptibility have been given by the CLSI for these newer fluoroquinolone compounds. Neither do we know anything about their potential breakpoints for reduced fluoroquinolone susceptibility.

Many previous studies have focused on in vitro efficacy of clinafloxacin and sitafloxacin on microbes other than salmonellas [23,27-29]. In these studies, the two new fluoroquinolones have had a better activity than the older preparations towards a variety of bacterial species, even including the ciprofloxacin-resistant strains. For example, clinafloxacin exhibited greater activity than older fluoroquinolones against ciprofloxacin-resistant Klebsiella pneumoniae and Enterobacter aerogenes isolates [27], and sitafloxacin proved superior to the others against ciprofloxacin-resistant isolates of several enterobacterial species [23]. Moreover, a number of studies have demonstrated the clinical efficacy of clinafloxacin in the treatment of systemic infections, including severe skin and soft tissue diseases and infective endocarditis, and in empirical therapy of febrile granulocytopenic patients [30-33]. These data are encouraging and suggest that the clinical efficacy of these novel fluoroquinolones should be tested also in salmonellosis.

The possible clinical usefulness of the two newer quinolones against Salmonella strains will also depend on the levels of the drug reaching the infecting organism. It has been shown in previous studies that in general, newer fluoroquinolones have equal or greater bioavailability compared with ciprofloxacin, which varies between 55 to $88 \%$ [34]. Limited data suggest that at least $70 \%$ of sitafloxacin is absorbed after an oral dose [35]. In one study, the absolute bioavailability of orally administered clinafloxacin was approximately $90 \%$ [36]. Thus, it is expected that these drugs will prove effective also in the oral treatment of salmonellosis.

\section{Conclusion}

Among the registered fluoroquinolone compounds in Finland, ciprofloxacin still appears to be the most effective drug for the treatment salmonella infections. Among the newer preparations, both clinafloxacin and sitafloxacin are promising based on in vitro studies, since they exhibited the lowest $\mathrm{MIC}_{50}$ and $\mathrm{MIC}_{90}$ values for all Salmonella isolates as well as for those with reduced fluoroquinolone susceptibility.

\section{Authors' contributions}

$\mathrm{PK}, \mathrm{SP}, \mathrm{PH}$ and $\mathrm{AH}$ planned and carried out the design of the study. SP and AH participated in laboratory studies and interpretation of the data. AS participated in the collection of Salmonella isolates and data, and was responsible for serotyping of Salmonella isolates. PK and AH wrote the first draft of the manuscript. All authors had intellectual contribution, and all read and approved the final manuscript.

\section{Acknowledgements}

We thank Erkki Nieminen for technical assistance and Tarja Heiskanen, Liisa Immonen, and Minna Lamppu for laboratory assistance.

\section{References}

I. Asperilla MO, Smego RA, Scott LK: Quinolone antibiotics in the treatment of Salmonella infections. Rev Infect Dis 1990, 1 2:873-889.

2. Clinical and Laboratory Standards Institute: Performance Standars for Antimicrobial Susceptibility Testing; Fifteenth Informational Supplement MI00-SI 5. Clinical and Laboratory Standards Institute. Wayne, PA, USA; 2005.

3. Crump JA, Barrett TJ, Nelson JT, Angulo FJ: Reevaluating fluoroquinolone breakpoints for Salmonella enterica serotype Typhi and for non-typhi Salmonellae. Clin Infect Dis 2003, 37:75-8I.

4. Hakanen A, Kotilainen P, Jalava J, Siitonen A, Huovinen P: Detection of decreased fluoroquinolone susceptibility in salmonellas and validation of nalidixic acid screening test. J Clin Microbiol 1999, 37:3572-3577.

5. Hakanen A, Kotilainen $P$, Huovinen $P$, Helenius $H$, Siitonen $A$ : Reduced fluoroquinolone susceptibility in Salmonella enterica serotypes in travelers returning from Southeast Asia. Emerg Infect Dis 200I, 7:996-1003.

6. Mølbak K, Baggesen DL, Aarestrup FM, Ebbesen JM, Engberg J, Frydendahl K, Gerner-Smidt P, Petersen AM, Wegener HC: An outbreak of multidrug-resistant, quinolone-resistant Salmonella enterica serotype typhimurium DTI04. N Engl J Med 1999, $34|:| 420-1425$

7. Ouabdesselam S, Tankovic J, Soussy C): Quinolone resistance mutations in the gyrA gene of clinical isolates of Salmonella. Microb Drug Resist 1996, 2:299-302.

8. Wain J, Hoa NT, Chinh NT, Vinh H, Everett MJ, Diep TS, Day NP, Solomon T, White NJ, Piddock LJ, Parry CM: Quinolone-resistant Salmonella typhi in Viet Nam: molecular basis of resistance and clinical response to treatment. Clin Infect Dis 1997, 25: 1404-1410.

9. Helms MP, Vastrup P, Gerner-Smidt P, Mølbak K: Excess mortality associated with antimicrobial drug-resistant Salmonella typhimurium. Emerg Infect Dis 2002, 8:490-495.

10. Kadhiravan T, Wig N, Kapil A, Kabra SK, Renuka K, Misra A: Clinical outcomes in typhoid fever: adverse impact of infection with 
nalidixic acid-resistant Salonella typhi. BMC Infect Dis 2005 , 5:37.

1I. Launay O, Van J-CN, Buu-Hoi A, Acar JF: Typhoid fever due to a Salmonella typhi strain of reduced susceptibility to fluoroquinolones. Clin Microbiol Infect 1997, 3:54I-543.

12. Le Lostec Z, Fegueux S, Jouve P, Cheron M, Mornet P, Boisivon A: Reduced susceptibility to quinolones in Salmonella typhi acquired in Europe: a clinical failure of treatment. Clin Microbiol Infect 1997, 3:576-577.

13. Pers C, Sogaard P, Pallesen L: Selection of multiple resistance in Salmonella enteritidis during treatment with ciprofloxacin. Scand J Infect Dis 1996, 28:529-53I.

14. Piddock LJ, Griggs DJ, Hall MC, Jin YF: Ciprofloxacin resistance in clinical isolates of Salmonella typhimurium obtained from two patients. Antimicrob Agents Chemother 1993, 37:662-666.

15. Rowe B, Ward LR, Threlfall EJ: Ciprofloxacin-resistant Salmonella typhi in the UK. Lancet 1995, 346: 1302.

16. Slinger R, Desjardins M, McCarthy AE, Ramotar K, Jessamine P, Guibord C, Toye B: Suboptimal clinical response to ciprofloxacin in patients with enteric fever due to Salmonella spp. with reduced fluoroquinolone susceptibility: a case series. $B M C$ Infect Dis 2004, 4:36.

17. Vasallo FJ, Martin-Rabadan P, Alcala L, Garcia-Lechuz JM, RodriguezCreixems M, Bouza E: Failure of ciprofloxacin therapy for invasive nontyphoidal salmonellosis. Clin Infect Dis 1998, 26:535-536.

18. Frost JA, Kelleher A, Rowe B: Increasing ciprofloxacin resistance in salmonellas in England and Wales 1991-1994. J Antimicrob Chemother 1996, 37:85-91.

19. Piddock LJ, Ricci V, McLaren I, Griggs DJ: Role of mutation in the gyrA and parC genes of nalidixic-acid-resistant salmonella serotypes isolated from animals in the United Kingdom. J Antimicrob Chemother 1998, 41:635-64I.

20. Threlfall EJ, Frost JA, Ward LR, Rowe B: Increasing spectrum of resistance in multiresistant Salmonella typhimurium. Lancet 1996, 347: 1053-1054

21. Hakanen A, Siitonen A, Kotilainen P, Huovinen P: Increasing fluoroquinolone resistance in salmonella serotypes in Finland during 1995-1997. J Antimicrob Chemother 1999, 43: I 45-I 48.

22. National Committee for Clinical Laboratory Standards: Methods for Dilution Antimicrobial Susceptibility Tests for Bacteria that Grow Aerobically, 6th ed. Approved standard M7-A6. National Committee for Clinical Laboratory Standards, Wayne, PA, USA; 2003

23. Milatovic D, Schmitz F-J, Brisse S, Verhoef J, Fluit AC: In vitro activities of sitafloxacin (DU-6859a) and six other fluoroquinolones against 8,796 clinical bacterial isolates. Antimicrob Agents Chemother 2000, 44: I102-1107.

24. Piddock LJV: Fluoroquinolone resistance in Salmonella serovars isolated from humans and food animals. FEMS Microbiology Reviews 2002, 26:3-16.

25. Griggs DJ, Gensberg K, Piddock LJ: Mutations in gyrA gene of quinolone-resistant Salmonella serotypes isolated from humans and animals. Antimicrob Agents Chemother 1996, 40:1009-1013.

26. Reyna F, Huesca M, Gonzalez V, Fuchs LY: Salmonella typhimurium gyrA mutations associated with fluoroquinolone resistance. Antimicrob Agents Chemother 1995, 39:1621-1623.

27. Brisse S, Milatovic D, Fluit AC, Verhoef J, Martin N, Scheuring S, Köhrer K, Schmitz F-J: Comparative in vitro activities of ciprofloxacin, clinafloxacin, gatifloxacin, levofloxacin, moxifloxacin, and trovafloxacin against Klebsiella pneumoniae, Klebsiella oxytoca, Enterobacter cloacae, and Enterobacter aerogenes clinical isolates with alterations in GyrA and ParC proteins. Antimicrob Agents Chemother 1999, 43:205I-2055.

28. Heinemann $B$, Wisplinghoff $H$, Edmond $M$, Seifert $H$ : Comparative activities of ciprofloxacin, clinafloxacin, gatifloxacin, gemifloxacin, levofloxacin, moxifloxacin, and trovafloxacin against epidemiologically defined Acinetobacter baumannii strains. Antimicrob Agents Chemother 2000, 44:22II-22I3.

29. Vila J, Ribera A, Marco F, Ruiz J, Mensa J, Chaves J, Hernandez G, Jiminez De Anta MT: Activity of clinafloxacin, compared with six other quinolones, against Acinetobacter baumannii clinical isolates. J Antimicrob Chemother 2002, 49:47I-477.

30. Glauser MP, Brennscheidt U, Cornely O, Grigg A, Figuera A, Keyserling $C$, Trostmann $U$, Welling $L$, Tack K: Clinafloxacin monotherapy $(\mathrm{Cl}-960)$ versus ceftazidime plus amikacin for empirical treatment of febrile neutropenic cancer patients. Clin Microbiol Infect 2002, 8: I4-2I.

31. Levine DP, Holley HP, Eiseman I, Willcox P, Tack K: Clinafloxacin for the treatment of bacterial endocarditis. Clin Infect Dis 2004, 38:620-631.

32. Siami G, Christou N, Eiseman I, Tack KJ, the Clinafloxacin severe skin and soft tissue infections study group: Clinafloxacin versus piperacillin-tazobactam in treatment of patients with severe skin and soft tissue infections. Antimicrob Agents Chemother 200I, 45:525-531.

33. Winston DJ, Lazarus HM, Beveridge RA, Hathorn JW, Gucalp R, Ramphal R, Chow AW, Ho WG, Horn R, Feld R, Louie T, Territo MC, Blumer JL, Tack KJ: Randomized, double-blind, multicenter trial comparing clinafloxacin with imipenem as empirical monotherapy for febrile granulocytopenic patients. Clin Intect Dis 200I, 32:38I-390.

34. Aminimanizani A, Beringer P, Jelliffe R: Comparable pharmacokinetics and pharmacodynamics of the newer fluoroquinolone antimicrobials. Clin Pharmacokinet 200I, 40:169-187.

35. Nakashima M, Uematsu T, Kosuge K, Umemura K, Hakusui H, Tanaka M: Pharmacokinetics and tolerance of DU-6859a, a new fluoroquinolone, after single and multiples oral doses in healthy volunteers. Antimicrob Agents Chemother 1995, 39:170- 174.

36. Randinitis EJ, Brodfuehrer JI, Eiseman I, Vassos AB: Pharmacokinetics of clinafloxacin after single and multiple doses. Antimicrob Agents Chemother 200I, 45:2529-2535.
Publish with Biomed Central and every scientist can read your work free of charge

"BioMed Central will be the most significant development for disseminating the results of biomedical research in our lifetime. "

Sir Paul Nurse, Cancer Research UK

Your research papers will be:

- available free of charge to the entire biomedical community

- peer reviewed and published immediately upon acceptance

- cited in PubMed and archived on PubMed Central

- yours - you keep the copyright 